\title{
APEROS DE LABRANZA: INSTRUMENTOS DE FORMALIZACIÓN DEL PAISAJE AGRARIO
}

\author{
Esther Isabel PRADA LLORENTE \\ Dr. Arquitecto, Universidad SEK, Segovia
}

\section{INTRODUCCIÓN}

Las transformaciones actuales de las economías, provocan rápidas e importantes mutaciones en la organización del territorio, olvidando cuál ha sido el proceso de formación del paisaje entendido como síntesis de aquél. En concreto, el olvido del proceso de formación del paisaje agrario, fruto de siglos de interacción del hombre con el medio físico sobre el que se asienta, supone una pérdida de nuestro patrimonio cultural.

El presente artículo analiza como dentro de ese proceso de formación la tecnología popular, trabajada y comprendida desde la utilización del dibujo a mano como herramienta de análisis y la información oral, fundamental para el entendimiento de la lingüística y las voces utilizadas, procedentes de épocas pretéritas que a lo largo de siglos han ido gestando un dialecto y un hacer característi$\cos$, ha sido la base para la construcción de lo que hoy contemplamos, ese entorno seminatural o paisaje sayagués por desgracia en período de extinción, dadas las intervenciones destructivas que tanto sobre el territorio como en los núcleos de poblamiento y en la propia arquitectura tradicional se están llevando a cabo, tales como las concentraciones parcelarias, las nuevas normas de delimitaciones de suelo que no tienen en cuenta las estructuras básicas de su paisaje, cortineos, tierras abiertas y dehesas, o el nuevo entendimiento de "chalets adosados" como aportación de la "arquitectura global" a un proceso rápido de pérdida total de identidad cultural.

El utillaje agrícola o apparium $^{1}$ utilizado hasta la introducción de maquinaria, en el caso de la comarca de Sayago al final de la década de los años sesenta del pasado siglo, es de una gran trascendencia para la organización del terrazgo remontándose su origen a época romana siendo de particular importancia el

\footnotetext{
${ }^{1}$ Apparium: aparius, aperius, en el bajo latín de Cataluña desde 963. El verbo aperar debió de existir en el catalán preliterario y luego se perdió. Appariare: emparejar, preparar, disponer derivado de par, paris, "par", pero el derivado aperamiento "arneses" ya en 1253. Aprear y apreo en autores de 1605 a 1750 parecen cruce de aperara y arrear. (DCEC, 1987)
} 
arado de madera, instrumento mediante el que se trabajaba tanto en el cortineo ${ }^{2}$ como en las "tierras abiertas"3. En las diferentes escalas de trabajo para el entendimiento de lo que significa el paisaje cultural de Tierra de Sayago que como categorías dentro del "sistema paisaje agrario", se desglosan en 1) escala territorial ,2) escala urbana y 3) escala arquitectónica (cfr. PRADA, 2005) se establece el subsistema "propiedad del terrazgo" basado en una estructura concéntrica de trazas circulares, que delimita los diferentes tipos de propiedad, privada y comunal, generando los tres tipos de paisaje en torno al núcleo de poblamiento: 1) paisaje de cortinas o campos cercados de propiedad privada, 2) paisaje de "tierras abiertas" de propiedad comunal y 3 ) paisaje de "dehesas" de propiedad privada en el límite del término municipal (cfr. PRADA, 2005), configurándose asimismo estos tipos de paisaje según los ciclos agrícolas, los sistemas de rotación de cultivos de "año y vez" o "al tercio" estrechamente vinculados al cultivo de la tierra y al sostenimiento de la cabaña ganadera. El instrumental agrícola y las técnicas de cultivo conservadas desde la Edad Media y que hasta no hace muchos años todavía podíamos contemplar, "azadas" y "azadones" para tierras pequeñas o huertos muy próximos a las viviendas, "hoces" para la "siega" y la fuerza de tiro de los animales con el arado de madera en las "tierras de pan llevar", o "marras" y "cuñas" en las dehesas para la extracción de leña, han intervenido decisivamente en la configuración de este paisaje.

El tiempo rural en Sayago es el impuesto por la naturaleza, repetido constantemente desde la Antigüedad, es su paisaje agrario, en el que la tierra concentraba los esfuerzos de la inmensa mayoría de los hombres, que obtenían de ella su sustento y sus recursos de todo tipo.

\section{UTILLAJE Y TERRITORIO}

\subsection{El cortineo}

Primera franja casi circular o traza en torno al núcleo de población que agrupa huertos, eras, cortinos ${ }^{4}$, prados y el resto de cortinas de propiedad privada cercadas con "paredes" de mampostería en seco, caracterizándose éstas por tener una mayor superficie que las primeras y por estar más alejadas del núcleo. Constituirían las primeras parcelaciones de propiedad privada surgidas de la to-

\footnotetext{
${ }^{2}$ Cortineo: Del latín cohor-tis. Recinto cerrado y cercado con pared de piedra. Tierras de cultivo en torno

a los núcleos de poblamiento de propiedad privada (cfr. PRADA, 2005).

${ }^{3}$ Tierras abiertas: Tierras objeto de la "labranza" o de "pan llevar" de propiedad comunal y situadas entorno al cortineo (cfr. PRADA, 2005).

${ }^{4}$ Cortinos: Cortinas de menor superficie muy próximas o pegadas a las edificaciones. El masculino es utilizado en Sayago de forma un tanto despectiva.
} 
talidad comunal perteneciente a un asentamiento, posiblemente desde época romana, aunque la información relativa a esta época, en cuanto a organización del terrazgo se refiere, es prácticamente inexistente para la comarca sayaguesa (cfr. PRADA, 2005).

Los huertos, prados y cortinos se trabajaban de distinta manera siendo también diferentes los productos obtenidos de los mismos, hortalizas caso de los huertos o "verde" para el ganado caso de los prados y cortinos.

El instrumental utilizado en estas tierras cercadas y cultivadas es en su práctica totalidad de madera, siendo solo de metal las hojas de guadañas, hoces, azadas, hachas y resto de útiles como azuelas, limitando sobremanera la capacidad individual de producción.

Para las tareas de cava y laboreo de los suelos en huertos y cortinos se utilizaban azadas y azadones. La azada del latín asciata o herramienta provista de un ascia a su vez, especie de hacha o azuela, está formado por una pala de hierro cuadrangular y un poco curvada siendo uno de sus lados cortante mientras que el opuesto forma un anillo donde se encaja el mango de madera (ver Fig.1).

Para segar el "verde" o "herrén" en prados y cortinos era utilizada la guadaña, derivado romance del gótico waithô que significa prado o pastizal (cfr. DCECH, 1987). La acción de cortar la hierba con guadaña solía decirse "segar con guadaña" o guadañar. Con ella se segaba la hierba a ras de tierra gracias a su cuchilla puntiaguda aunque menos corva y más ancha que la de la hoz y sujeta por su parte ancha a un mango largo de madera. Ligado a la guadaña y debido al desgaste que experimentaba durante su utilización, el cuerno de afilar ${ }^{5}$ con piedras de esmeril y agua en su interior que atados al pantalón de su portador, servían para afilar la hoja de metal de la misma (ver Fig.2).

El instrumental para la recolección, se completaba con algunos útiles que facilitaban el manejo del grano y la paja en las "eras" comunales o en los prados de propiedad privada anejos a las viviendas, tornaderas, bieldos, bieldas, palas y raspaderas.

La tornadera, del latín tornus o instrumento del torneador o tornero, en Sayago es el instrumento de madera que utilizan los labradores para dar la vuelta a la mies una vez trillada (ver Fig.3).

\footnotetext{
${ }^{5}$ Cuerno de afilar: asta de toro o vaca de raza autóctona o sayaguesa vaciado en su interior para poder introducir en ella las piedras de afilar
} 
El bieldo, o instrumento de madera compuesto por un palo largo, otro atravesado en uno de sus extremos y los fijos en el transversal en forma de dientes, servía para "aventar las mieses", del latín ventilare, "agitar en el aire" (cfr. DCECH, 1987). La acción de aventar para separar el grano de la paja se denominaba "limpiar" o bieldar, realizándose esta labor a primeras horas de la mañana e incluso de madrugada los días del verano que soplaba el aire de arriba. Una vez separada la paja con la bielda, que a diferencia del bieldo tiene seis puntas con dos palos atravesados, se cargaba en el carro para su transporte y posterior almacenamiento en los pajares de las casas de labranza (ver Fig.4).

La pala toda ella de madera se utilizaba para bieldar en la parva ${ }^{6}$ lo trillado.

La raspadera, para "raspar" o recoger en la "era" los granos de cereal que se han quedado diseminados una vez "juntados los muelos" (ver Fig.5).

Por último y en esta primera traza del cortineo se realizaba la trilla, de trilhar, pisar (cfr. DCECH, 1987), una vez esparcidos los haces de las parvas en las "eras", mediante el trillo (ver Fig.6 y Fig.7). Consta de varios tablones unidos arriostrados por otros transversales, a los que por una de sus caras se encajan trozos de pedernal con los que se corta la paja y se separa del grano. Mediante un clavo denominado trépago se engancha al trillo el cambizo, especie de viga larga y un poco curvada que se une en su otro extremo al yugo de uncir ${ }^{8}$ las vacas sayaguesas a través de un anillo de madera, el barzón (ver Fig.8). A su vez la pareja de vacas era uncida al yugo mediante unas correas fuertes y anchas de "cuero" denominadas coyundas.

\subsection{Las tierras abiertas}

Segunda traza de organización del terrazgo en torno al núcleo de poblamiento. Paisaje de campos abiertos sobre los que se lleva a cabo la rotación de cultivos según el sistema de "año y vez" de forma mancomunada, con la partición del término en "hojas" según los caminos existentes, dividiendo el término en dos partes aproximadamente iguales para un mejor aprovechamiento agrícola y pecuario.

Para la siega se utilizaba la $\mathbf{h o z}$, trabajo lento y pesado que durante los meses de Junio y Julio ocupaba prácticamente la totalidad del tiempo o como decían en Sayago, "desde la salida del sol hasta la puesta". Con la hoz se cortaba la caña de cereal a una cierta distancia por debajo de la espiga de forma que una vez

\footnotetext{
${ }^{6}$ Parva: Conjunto de haces de cereal depositados en la era

${ }^{7}$ Muelo: Monticulo de trigo, cebada o centeno, que queda una vez separado el grano de la paja

${ }^{8}$ Uncir: Unzir aparece en 1240 en el Fuero Juzgo. Del latín Jungere que significa juntar, reunir
} 
concluida la siega, el ganado se alimentaba con lo que aún permanecía en el suelo, el rastrojo, denominándose esta operación "derrota de mieses" (cfr. PRADA, 2005).

El arado romano o de madera, consistente en un palo excavador en cuya parte final se encuentra embutida la reja, pieza metálica de forma triangular (ver Fig.9). Ésta, no voltea el suelo sino que dibuja un suco o surco apartando la tierra por igual a uno y otro lado, denominándose cerro la cuña de tierra que queda entre dos surcos. Las "tres aradas", relvar o dar la primera reja de arado para levantar el barbecho, vimar o segunda y terciar o tercera arada 9 que se realizaban antes de la "siembra" en el mes de septiembre, se efectuaban con el arado descrito mientras que, para la operación de aricar o arada superficial posterior no se utilizaba reja. El arado se une al yugo (ver Fig. 10 y Fig.11), formado por la pareja de vacas sayaguesas, por medio del cabijal, pieza única de madera que se engancha a aquél mediante la clavija. Las partes del arado según los informantes de Sayago consultados son las siguientes: a) mancera, derivado del término latino manucium que significa mango (cfr. DCECH, 1987), se trata de la esteva o manija del arado, b) cama, del céltico cambos curvo, pieza de madera encorvada que se apoya en el suelo, c) dental, parte del arado sobre la que se superpone la reja, d) reja, pieza metálica que horada el terreno, e) cabijal, pieza de madera que une el arado al yugo, f) telera, del término latino telum dardo, barra de hierro que arriostra la cama y el dental para asegurar y afirmar la reja, g) bilortas, dos anillas de hierro que sujetan el cabijal a la cama, h) orejeras, pequeñas piezas de madera situadas en los laterales del dental, i) cuñas, de madera para mayor sujeción entre la cama y el cabijal a través de las bilortas, o entre la mancera y el dental, j) calzas, trozos de hierro que se añaden a la parte inferior del dental para evitar su desgaste (ver Fig.9 y ver Fig.12).

Asociada al manejo del arado la aguijada, del término latino aquileata (cfr. DCECH, 1987), permitía el corte de las malas hierbas que iban sobresaliendo en el terreno a medida que se avanzaba con aquél. Consta de una vara provista de aguijón en un extremo para "pinchar" a las vacas y que su avance fuera más rápido y el recatón que podía ser plano o curvo, especie de hacha pequeña incrustada en el otro extremo de la vara (ver Fig.13).

La rastra para "arrastrar" y "descabezar los cerros" una vez sembrados, consta de una viga larga de madera de forma cuadrangular a la que se sube el labrador para conseguir más carga y así "arrastrar" mejor el terreno. Se engancha al

\footnotetext{
${ }^{9}$ Relvar: Ralbar. Portugués relvar. Del lat. Relevare "levantar, solevantar". Fuero de Zamora: "bonos barbechos, relvados, bimados y terciados" (cfr. DCECH, 1987).
} 
yugo mediante el cabijal a través de otra pieza de madera como la cama del arado, por último dos barras metálicas sujetan ésta a la rastra (ver Fig.14).

\subsection{La dehesa}

La dehesa es la gran finca rústica particular, destinada al triple aprovechamiento agrícola, ganadero y forestal. Última traza en torno al núcleo de poblamiento y situada en los límites del término municipal sirve fundamentalmente para pasto de la cabaña ganadera así como para la obtención de leña a partir de las especies vegetales predominantes, roble (Quercus pyrenaica) y encina (Quercus rotundifolia) (cfr. PRADA, 2005). En la dehesa se realizaban los "carboneros", montones de leña que se quemaban para la obtención del cisco, material imprescindible para calentar los "braseros" en el invierno.

La marra, mazo de hierro que servía para "sacar piedra", también se utilizaba para hacer leña golpeando las cuñas metálicas dispuestas en el árbol previamente talado (ver Fig.15).

Para transportar la leña desde la dehesa hasta el núcleo de poblamiento, así como para acarrear la paja desde la era hasta los pajares de las casas para su guarda, o para el traslado de los restos orgánicos de los muladares a las tierras de cultivo para su fertilización, se utilizaba el carro tirado por la pareja de vacas (ver Fig.16).

Según los informantes consultados, el cuerpo del carro está formado por la engarilla, de angariae, "prestaciones de transporte en caballería o en carro" (cfr. DCECH, 1987) o armazón del mismo compuesto a su vez por un entramado de largueros y "costillas" en los que se anclan una anillas metálicas, las estaconeras, para la introducción en ellas de unos palos de madera que aumentaban la capacidad del carro cuando la necesidad obligaba por lo general, para el acarreo de la paja en el verano. El centro de la rueda, de donde parten los rayos de la misma, se denomina bocamaza y la pieza metálica donde se engancha al $\mathrm{ca}$ rro, buje, del latín buxis, pieza cilíndrica que guarnece el cubo de la rueda. La chaveta sería la clavija o pasador que se coloca en el orificio del buje para impedir que se salga la rueda. En la denominada viga (ver Fig.17) del carro también aparecen una serie de elementos con sus denominaciones características, como el tentemozos, el esternón, el tesador y el sobeyuelo, piezas todas ellas situadas en la parte más próxima del yugo (ver Fig.18) y relacionadas con el atado de este a la pareja y al carro.

Asociados a éste, el tablero o tapa del carro para cerrarlo (ver Fig.19) y el gato de "untar" para levantar las ruedas y poder dar grasa en el buje para el mantenimiento de éstas (ver Fig.20). 


\section{LAS LABORES AGRÍCOLAS}

La característica agropecuaria tradicional de este ámbito geográfico supone el aprovechamiento comunal de tierras, pastos y monte, así como el sistema de "cotos redondos" o "dehesas", características que explican el origen de los términos municipales en tanto que tierras establecidas por el concejo para la realización de dichas prácticas agropecuarias (cfr. PRADA, 2005). El concejo o asamblea de los habitantes de un mismo núcleo de población fijaba los términos de las tierras del poblado a través de los "herederos" y omnes buenos, espacios a los que se extendían los usos y prácticas comunales siendo este el comienzo desde el que se empezó a construir el municipio. La labranza, práctica comunal institucionalizada con el feudalismo iniciado con la aparición de documentos escritos en el S. XII, delimita términos y compartimenta el antiguo y compacto espacio ganadero de Tierra de Sayago a favor de los concejos de cada aldea aproximadamente hacia el S. XIII ( cfr. MARTíN, 1996) amén de la apropiación por particulares de parte de los terrenos primigenios comunales, los denominados cotos redondos o dehesas. Las tierras se sorteaban entre los vecinos del concejo así como el período de pasto en los pastos comunales y la recogida de la cosecha, implicando la aparición de los concejos, la delimitación y apropiación por parte de éstos de los pastos y las tierras objeto de la labranza.

Por otra parte, las faenas comunales, jeras o fajinas aunque no exactamente tareas agrícolas, si suponían el trabajo de la comunidad para la conservación de los servicios públicos. El cuidado de los caminos, las fuentes, la buena conservación de las eras o el arreglo del monte eran trabajo de faena, convocadas por el Ayuntamiento correspondiente con la frecuencia considerada por la municipalidad, consistiendo dichas faenas en la compostura de estos servicios, su limpieza y arreglo, con la participación de todos los vecinos.

A modo de esquema y según la información oral transmitida se especifican las principales labores en cada una de las "hojas" del bienio agrario, relatadas previamente por la asociación de cada una con el utensilio o apero necesario para dicha tarea.

Por otra parte de los principales trabajos de recolección, la siega, la trilla y el cribado del cereal realizado con la zaranda, formada por un anillo de madera al que se la cosía una piel de vaca horadada; las dos últimas no aparecen en dicho esquema por ser labores que se realizan en las "eras" dentro del núcleo de poblamiento, no en alguna de las dos "hojas" de las tierras abiertas ${ }^{10}$. Tampoco

\footnotetext{
${ }^{10}$ Para un mejor entendimiento sobre el significado de la hoja y la "derrota de mieses" aplicados al término municipal de Escuadro, consultar en $C y T \mathrm{n}^{\circ}$ 144. "Paisaje agrario: antropología de un territorio“"
} 
aparece la "siega con guadaña" por realizarse asimismo dentro de dicho núcleo en los prados o cortinos habilitados para tal efecto y por no considerarse exactamente como "recolección" sino como "verde" o alimento para el ganado.

AÑO AGRARIO: Trabajos agrícolas en cada hoja.

\begin{tabular}{|c|c|c|}
\hline 1er Año & Hoja del Pan & Hoja de Barbecho \\
\hline Septiembre & Sembrar & Algarrobas/rastrojo \\
\hline Octubre & Sembrar & Algarrobas/rastrojo \\
\hline Noviembre & Arrastrar & --- \\
\hline Diciembre & --- & --- \\
\hline Enero & --- & --- \\
\hline Febrero & Aricar & --- \\
\hline Marzo & Aricar & $\operatorname{Relvar}\left(1^{\mathrm{a}}\right.$ arada $)$ \\
\hline Abril & --- & --- \\
\hline Mayo & --- & $\operatorname{Vimar}\left(2^{\mathrm{a}}\right.$ arada $)$ \\
\hline Junio & Segar (a finales) & Terciar $\left(3^{\mathrm{a}}\right.$ arada $)$ \\
\hline Julio & Segar (hasta Santiago) & --- \\
\hline Agosto & Rastrojo & --- \\
\hline $2^{\circ}$ Año & Hoja de Barbecho & Hoja del Pan \\
\hline Septiembre & Algarrobas/rastrojo & Sembrar \\
\hline Octubre & Algarrobas/rastrojo & Sembrar \\
\hline Noviembre & --- & Arrastrar \\
\hline Diciembre & --- & --- \\
\hline Enero & --- & --- \\
\hline Febrero & --- & Aricar \\
\hline Marzo & Relvar ( $1^{\mathrm{a}}$ arada $)$ & Aricar \\
\hline Abril & --- & --- \\
\hline Mayo & $\operatorname{Vimar}\left(2^{\mathrm{a}}\right.$ arada $)$ & --- \\
\hline Junio & Terciar $\left(3^{\mathrm{a}}\right.$ arada $)$ & Segar (a finales) \\
\hline Julio & --- & Segar (hasta Santiago) \\
\hline Agosto & --- & Rastrojo \\
\hline
\end{tabular}

Esquema de tareas agrícolas según el sistema de rotación de cultivos de "año y vez". FUENTE: Informantes de Escuadro de Sayago. José Campos Pelayo y Delia Campos Prada. Marzo 2005. Elaboración propia.

\subsection{La "siega"}

Para explicar el proceso de siega nada más aclaratorio que la trascripción de la información oral relatada por un labrador de Escuadro de noventa y cinco años, que en sus propias carnes sintió el peso de aquellos trabajos. Se trata de la relación tradicional mantenida por labradores de Sayago y cuadrillas de segado- 
res portugueses que iban a trabajar en el verano, según las supuestas mejores condiciones de vida por este lado de la "raya"11.

"Los portugueses venían a Sayago a trabajar, en busca de "siega". El medio de transporte utilizado eran "dos caballerías" con las que tenían que atravesar el Duero ayudados por "sogas". Encima de dichas caballerías traían su propio equipo, compuesto por "hoces" y "piedras de mano" para afilar. Venían en grupos de seis personas, cuatro para segar y dos para "atar", estas últimas denominadas atiñas normalmente mujeres, que "ataban" lo que segaban sus compañeros y colocaban en haces. Las otras cuatro personas, independientemente podían ser hombres o mujeres. Lo que segaban y ataban (trigo, cebada y centeno) se denominaba sucada o un viaje de ida y otro de vuelta a lo largo de una "tierra" o longuero, ubicada en las "tierras abiertas" o "comunales" de cualquier municipio de Sayago. Normalmente estaban por esta parte de la "raya" aproximadamente un mes y medio que era lo que duraba la siega.

"En la tierra se hacían tres comidas, desayuno, almuerzo y merienda que era transportada hasta allí a lomos de caballería (asnos) por "el ama de la tierra". Se acostaban la siesta debajo de un "roble" aproximadamente una hora, igual al resto de labradores sayagueses y pasaban la noche encima de sacos de paja, en pajares, corrales, o si el dueño de la tierra tenía camas suficientes, en ellas dentro de la casa. Las cenas se realizaban asimismo en la casa. Las atiñas lavaban la ropa en las fuentes públicas por la tarde, cuando terminaban la jornada, que duraba desde la salida del sol hasta "la puesta".

"La siega se realizaba a mano y con hoz, que se afilaba al finalizar cada suca$d a$. Las piedras de afilar eran de granito extraídas de canteras muy abundantes por toda la comarca de Sayago. Los dos segadores que de forma simultánea trabajaban, colocaban de manera atravesada en el suco o surco arado, las denominadas manadas que a su vez, formaban gavillas. La atiña que venía más retrasada, recogía un montón de gavillas con las que confeccionaba un haz atado con pajas de centeno, atado que se denominaba bencejo. Y así sucesivamente de un "patrón" a otro hasta la finalización de la siega".

"Por otra parte los portugueses llevaban el pan (fundamentalmente de centeno) de Bermillo o de los pueblos más próximos a la "raya", dada la escasez y mala elaboración en su comarca. En Sayago aún realizándose también este tipo de pan, normalmente se hacía en cada casa con harina de trigo".

"Otro tipo de trabajo que efectuaban era la venta de sillas realizadas con juncos y madera de encina o negrillo y la construcción de paredes de piedra. Esta

${ }^{11}$ Transcripción en ANEJO de Paisaje agrario: antropología de un territorio 
tarea la siguen ejecutando en la actualidad, dada la falta e mano de obra y desinterés existente, tanto por parte de la gente en Sayago como por parte de la administración, por este tipo de cerramiento tradicional de las tierras de cultivo".

\subsection{Actividad agraria y pecuaria}

La forma de compaginar la actividad agraria y pecuaria se producía a través de la organización comunal del trabajo y la tierra. El mismo informante de Escuadro nos relata como se realiza la "derrota de mieses" para la cabaña ganadera de un municipio y poder mantener la fertilización del suelo para un mejor rendimiento agrícola ${ }^{12}(12)$.

"Primero pastan en los valles las vacas y después, las ovejas, porque las primeras no lo hacen por aquellos lugares por donde han pasado estas últimas. A primeros de Mayo se "soltaba la hoja" para las vacas en aquellos valles situados en "los panes" o tierras sembradas, mientras que en los valles y tierras del barbecho estaban las ovejas.

Los valles de la "hoja" sembrada o "panes" eran pastados durante quince días aproximadamente pasados los cuales, se "guardaba". A finales del mismo mes de Mayo, se "soltaban los valles" otra vez más para las vacas con la misma duración de tiempo para el pasto.

Finalizada la siega en el mes de Julio se "soltaba la espiga" -el espigadero-, para toda la cabaña ganadera del municipio y esta vez en todo el término, es decir, en las dos "hojas", "panes" y barbecho hasta la llegada de la siembra en el mes de Octubre, en la "hoja" correspondiente de ese año es decir, en el anterior barbecho".

\section{EPÍLOGO}

La interpretación "hermenéutica" del territorio pasa por el conocimiento del lenguaje utilizado que permita descifrar, para ir más allá respecto a la mera contemplación del paisaje, la identidad del grupo social que se ha constituido en un determinado ámbito espacial. Asimismo la lectura del "sistema paisaje agrario" que nos viene dado, lleva implícita una revalorización de la tradición, asumiendo la historia en su integridad, resultando de especial importancia la transmisión oral de conocimientos antes de su pérdida irremediable.

El utillaje agrícola estudiado y relacionado con cada una de las diferentes trazas territoriales, cortineos, tierras abiertas y dehesas, así como con el núcleo de

\footnotetext{
${ }^{12}$ Trascripción completa en I Congreso Nacional de Vías Pecuarias. Vías pecuarias: caminos de historia, perspectivas para un futuro sostenible del paisaje.
} 
poblamiento que configuran la totalidad del sistema, representa el instrumental con el que se ha intervenido tradicionalmente sobre un soporte, llegando a configurar junto con éste la singularidad y característica de un lugar, el paisaje cultural de Tierra de Sayago.

Esta singularidad conforma la personalidad de esta comunidad distinguiéndola de las demás, haciendo que sea esta y no otra, esa personalidad es la que debe contribuir al enriquecimiento de opciones de futuro.

La idea del territorio, del paisaje agrario como sistema, necesita del conocimiento multidisciplinar para un cambio de mentalidad fundamentalmente desde la administración, que permita avanzar hacia la sostenibilidad del medio rural como nuevo paradigma territorial.

\section{BIBLIOGRAFÍA}

Árguedas, J.M (1968). Las comunidades de España y del Perú. Perú. Universidad Mayor de San Marcos. Ed.: Ediciones Cultura Hispánica, del Instituto de Cooperación Iberoamericana y Ministerio de Agricultura, Pesca y Alimentación (1987).

CAntera Montenegro, E (1997). La agricultura en la Edad Media. Madrid. Arco/Libros, S.L.

CARo BAroja, J. (1981). Los pueblos de España. Ed. Istmo. Madrid.

CASTAÑo Blanco, J.M. (1992). Sayago a la luz del catastro de Ensenada. Respuestas Generales. Zamora. Colección de etnografías en las comarcas zamoranas. Caja España.

Costa, J (1915). Colectivismo agrario en España. Biblioteca Costa. Madrid.

Del BRío Mateos, A. M. (1998). Apuntes históricos de Zamora y su tierra. Zamora.

DicCIONARIO CRíTICO ETIMOLÓGICO CASTELLANO E HISPÁNICO (DCECH) (1980-1983): Corominas, Joan, dir. Ed. Gredos, reimpr., Madrid. 1986-1987. 5 vols.

Diccionario De la Real ACademia Española De La Lengua (Drae) (1984). Vigésima edición. Madrid. 2 vols.

FERNÁNDEZ, L. (1976). Farsas y églogas. Edición de Mª Josefa Canalleda. Ed. Castalia. Madrid.

GÓMEZ Moreno, M. (1927). Catálogo monumental de la provincia de Zamora. Edición Facsímil de 1980. León. Ed. Nebrija.

Instituto De Estudios Zamoranos Florián De OCAMPo, (1990). Primer Congreso de Historia de Zamora. Actas. Diputación de Zamora.

LóPEZ TRIGAL, L. (1994). Zamora, un espacio de frontera. Fundación Rei Afonso Henriques. Zamora.

MajadA NeILA, J (1983). Fuero de Zamora. Salamanca. Gráficas Cervantes.

MANGAS NAVAS, J.M. (1992). Vías pecuarias. Instituto Nacional para la conservación de la Naturaleza.

MARTín FERrero, Ma ${ }^{a}$. A. (1992). Pervivencia de una agricultura tradicional en la comarca de Sayago. 
MARTín ViSO, I. (1996). «Una comarca periférica en la Edad Media: Sayago, de la autonomía a la dependencia feudal». Studia Histórica. Historia Medieval. Vol.14. Ediciones Universidad de Salamanca.

MARTín ViSO, I. (2000). Poblamiento y estructuras sociales en el norte de la Península Ibérica. Siglos VI-XIII. Edición Universidad de Salamanca. Salamanca.

PRADA LLORENTE, E. I. (2005). «Paisaje agrario: antropología de un territorio. Ciudad y Territorio». Estudios territoriales $\mathrm{n}^{\circ}$ 144. Ministerio de la Vivienda. Madrid.

PRADA LLORENTE, E. I. (2005). «Paisaje agrario: el "recurso" para un futuro sostenible del medio rural». X Coloquio Ibérico de Geografía. Universidad de Évora. Évora.

PRADA LLORENTE, E. I. (2005). «El paisaje como archivo del territorio». Cuadernos de investigación urbanística. Ci[ur]40. Instituto Juan de Herrera. Departamento de Urbanismo. E.T.S.A. Madrid.

PRADA LlORENTE, E. I. (2006). «Vías pecuarias: Caminos de historia, perspectivas para un futuro sostenible dl paisaje». Actas del I Congreso Nacional de Vias Pecuarias. Ministerio de Medio Ambiente. Madrid.

RODRÍGUEZ FERNÁNDEZ, (1990). Los Fueros de la provincia de Zamora. Junta de Castilla y León.

SÁNCHEZ GÓMEZ, L.A. (1993). Las dehesas de Sayago. Explotación, trabajo y estructura social. Zamora. Caja España. 

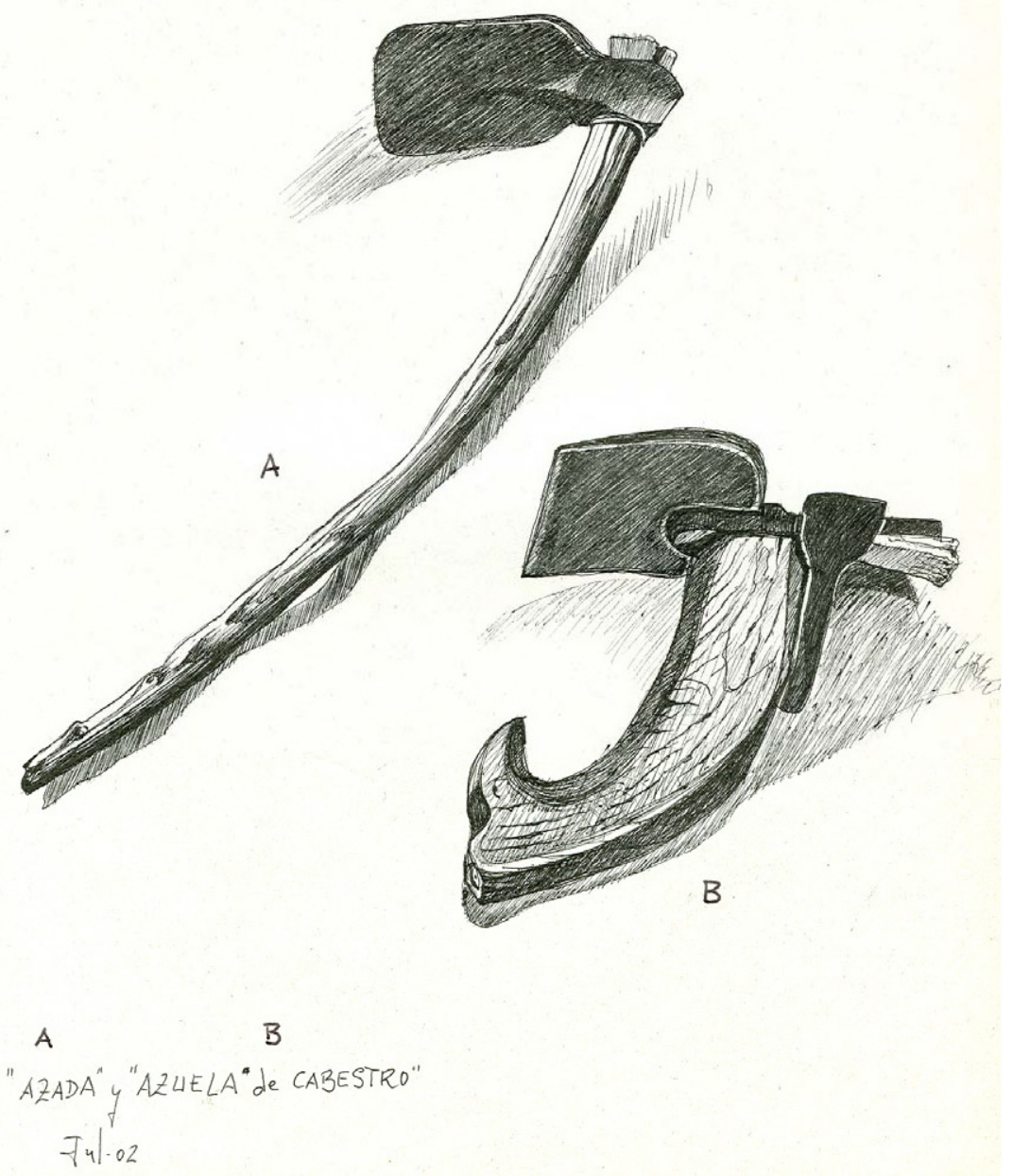

Fig. 1. Azada y azuela. Hierro y madera. E.I. Prada 

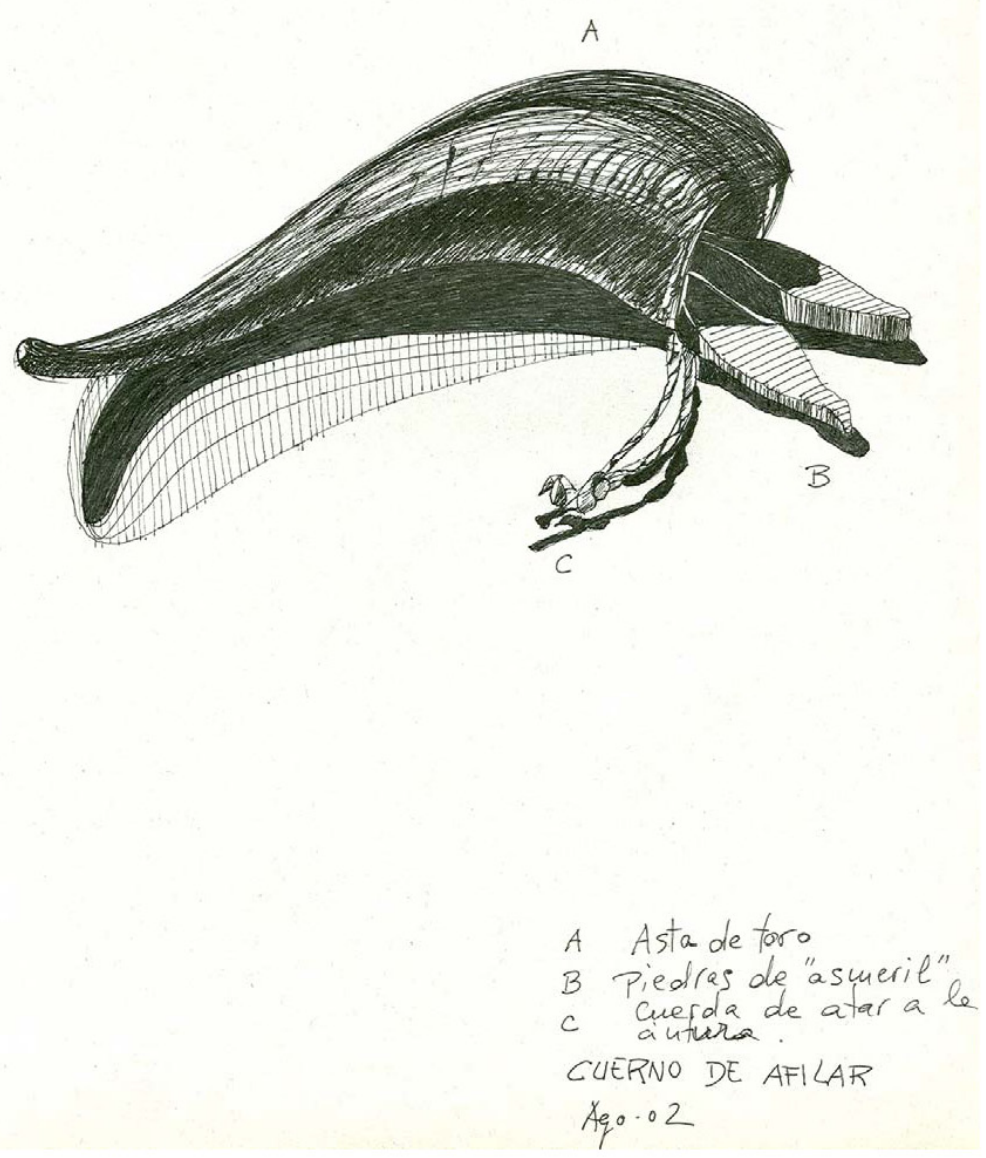

Fig. 2. Cuerno de afilar con piedras de esmeril. Asta de vaca. E.I. Prada 


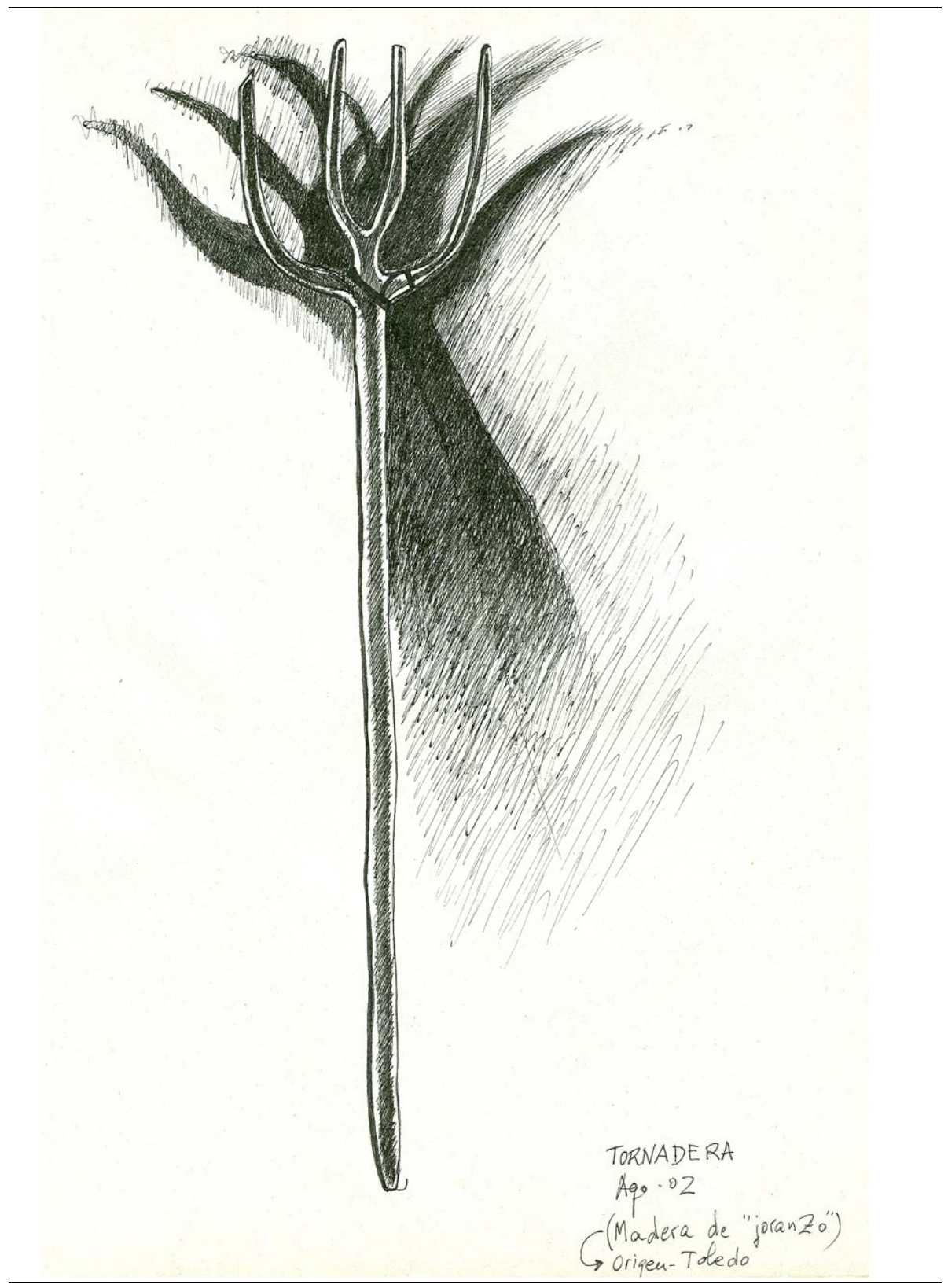

Fig. 3. Tornadera. Madera de una sola pieza. E.I.Prada 


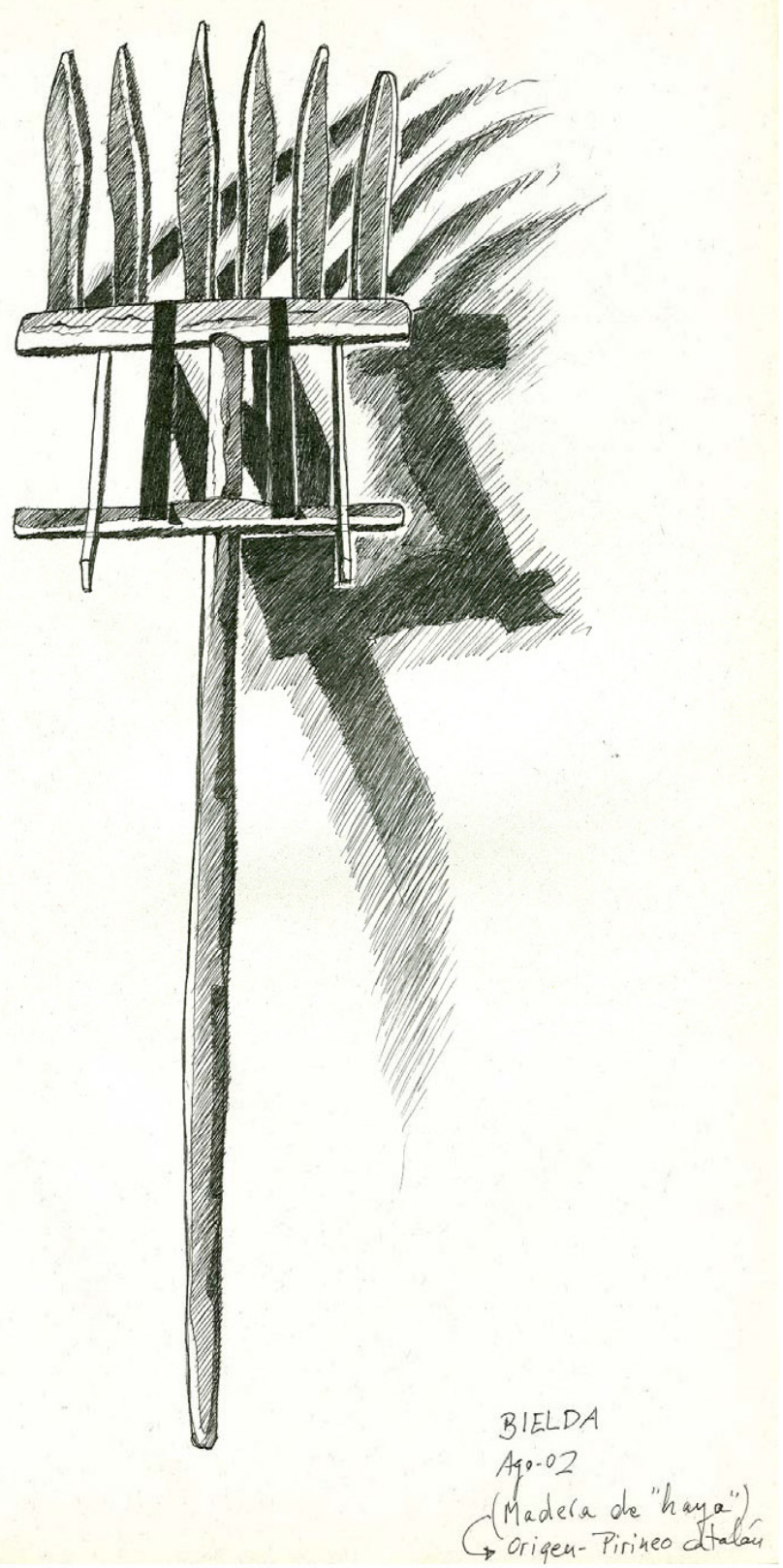

Fig. 4. Bielda. Madera. E.I.Prada

Polígonos. Revista de Geografia, 16 (2006); pp. 135-166 


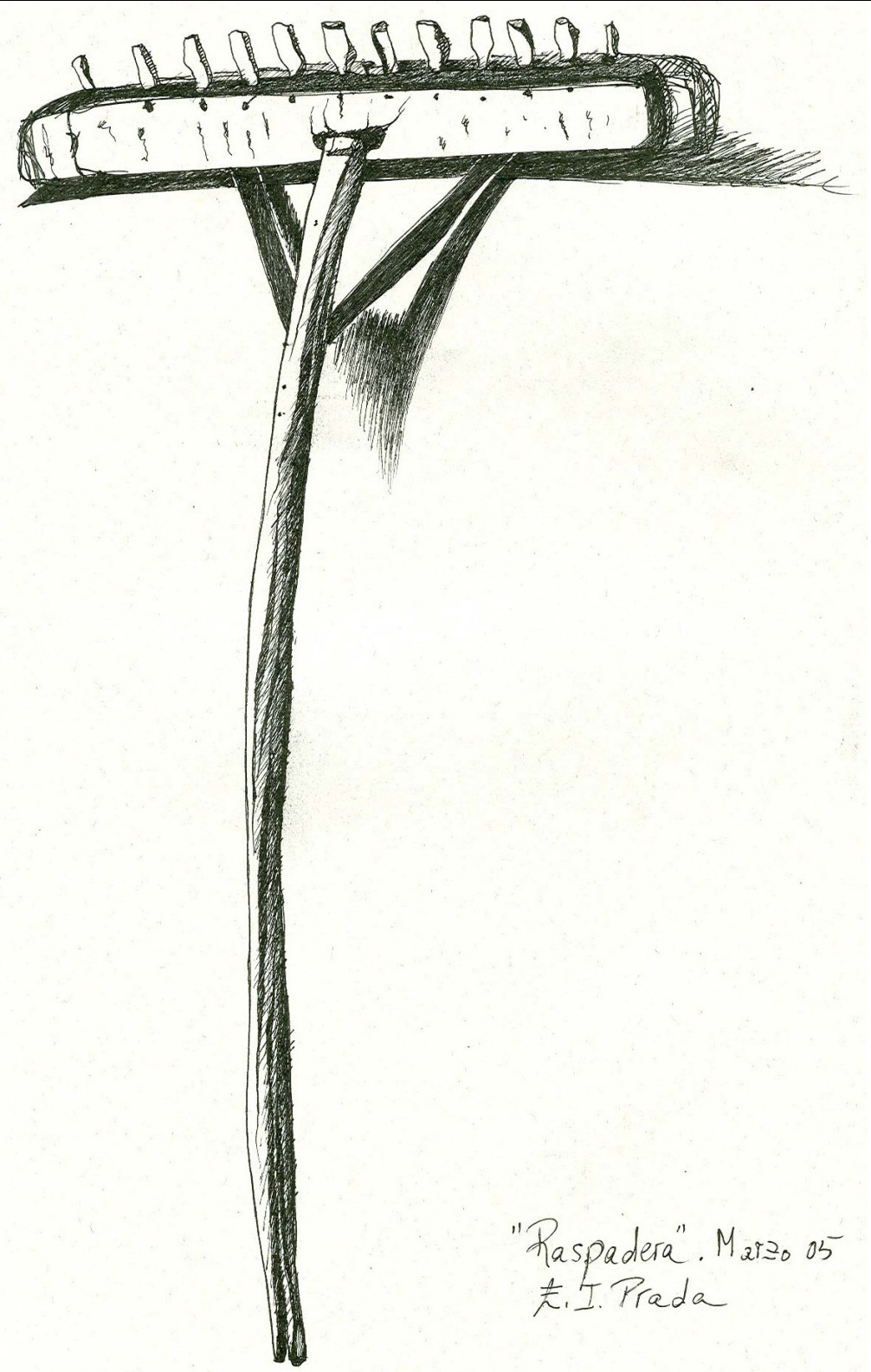

Fig. 5. Raspadera. Madera. E.I.Prada 


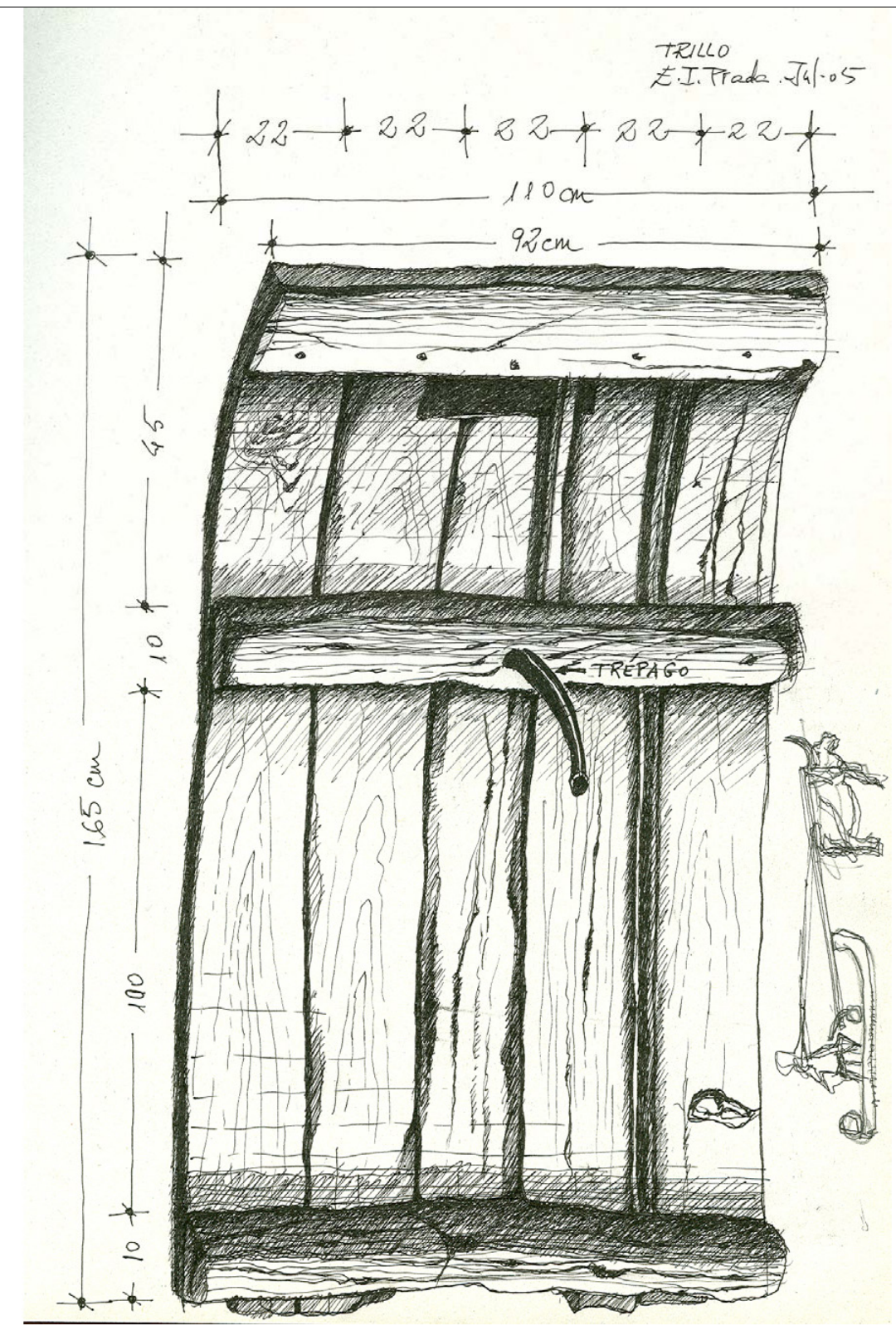

Fig. 6. Parte anterior del trillo. Madera. E.I.Prada 


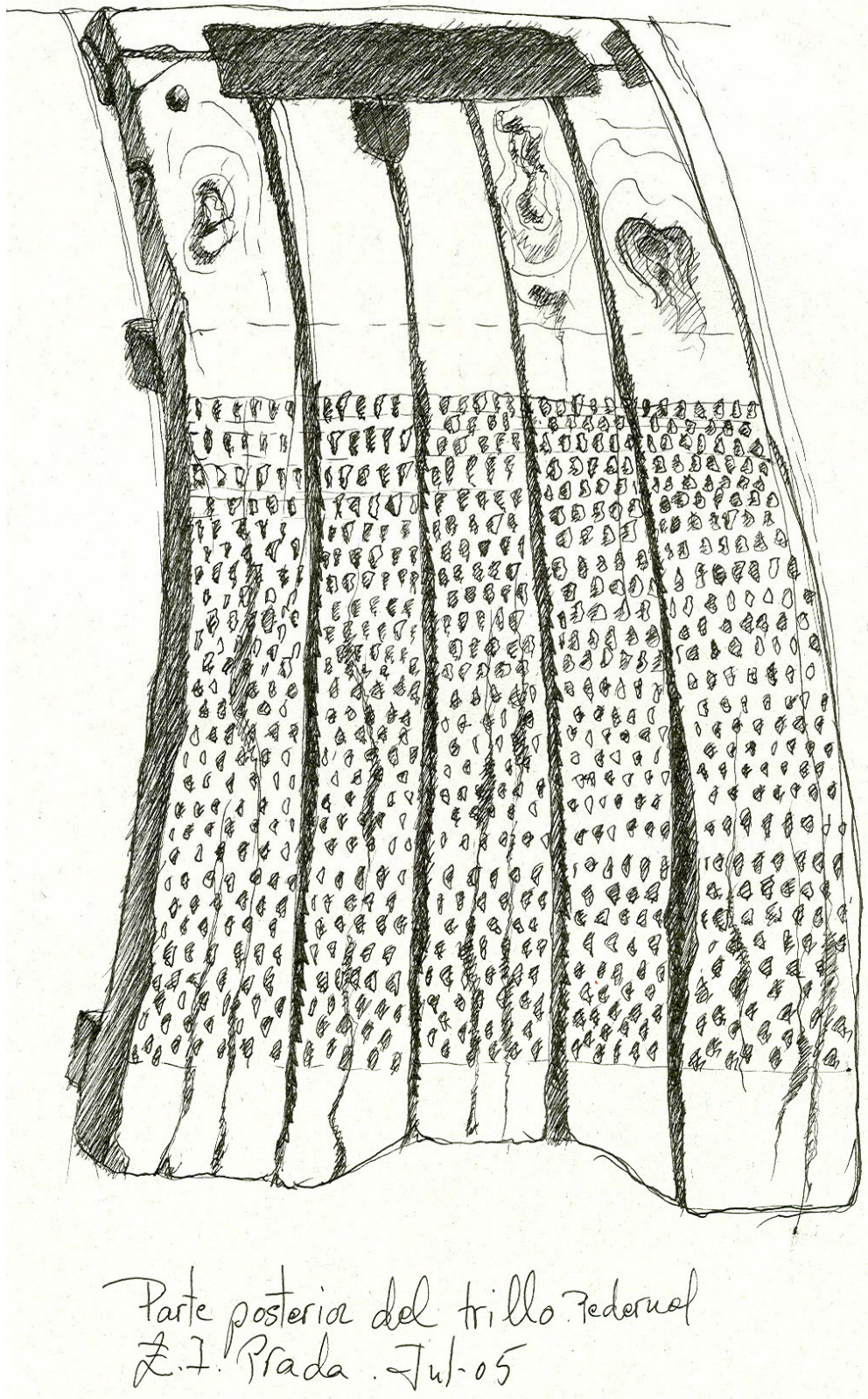

Fig. 7. Parte posterior del trillo. Madera y pedernal. E.I. Prada 


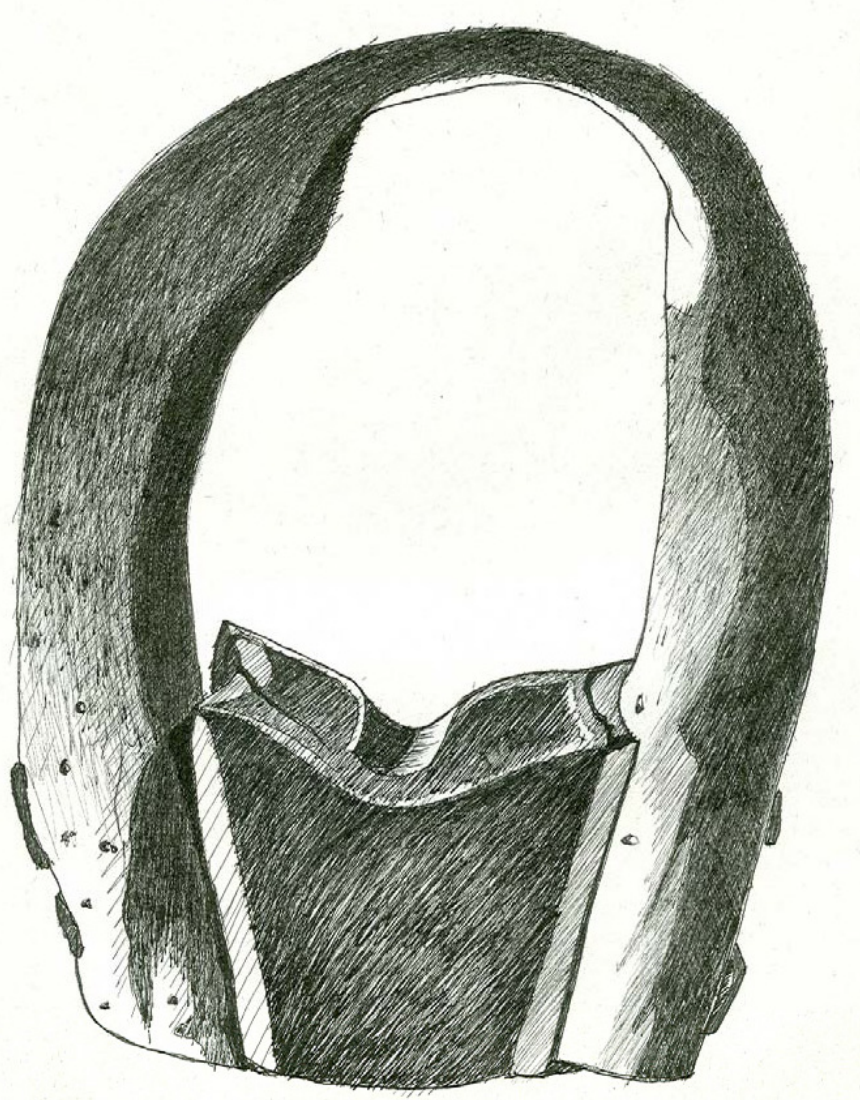

\section{BARZÓN}

$$
\begin{aligned}
& \text { Ago-02 } \\
\rightarrow & \text { (Madera de "joranzo") } \\
\rightarrow \text { Origen-Toledo. } &
\end{aligned}
$$

Fig. 8. Barzón. Madera. E.I. Prada

Polígonos. Revista de Geografia, 16 (2006); pp. 135-166 

A CAMA
B DENTAL
C PINA
D BILORTA
E OREJERA
F CALZAS
$G$ TELERA

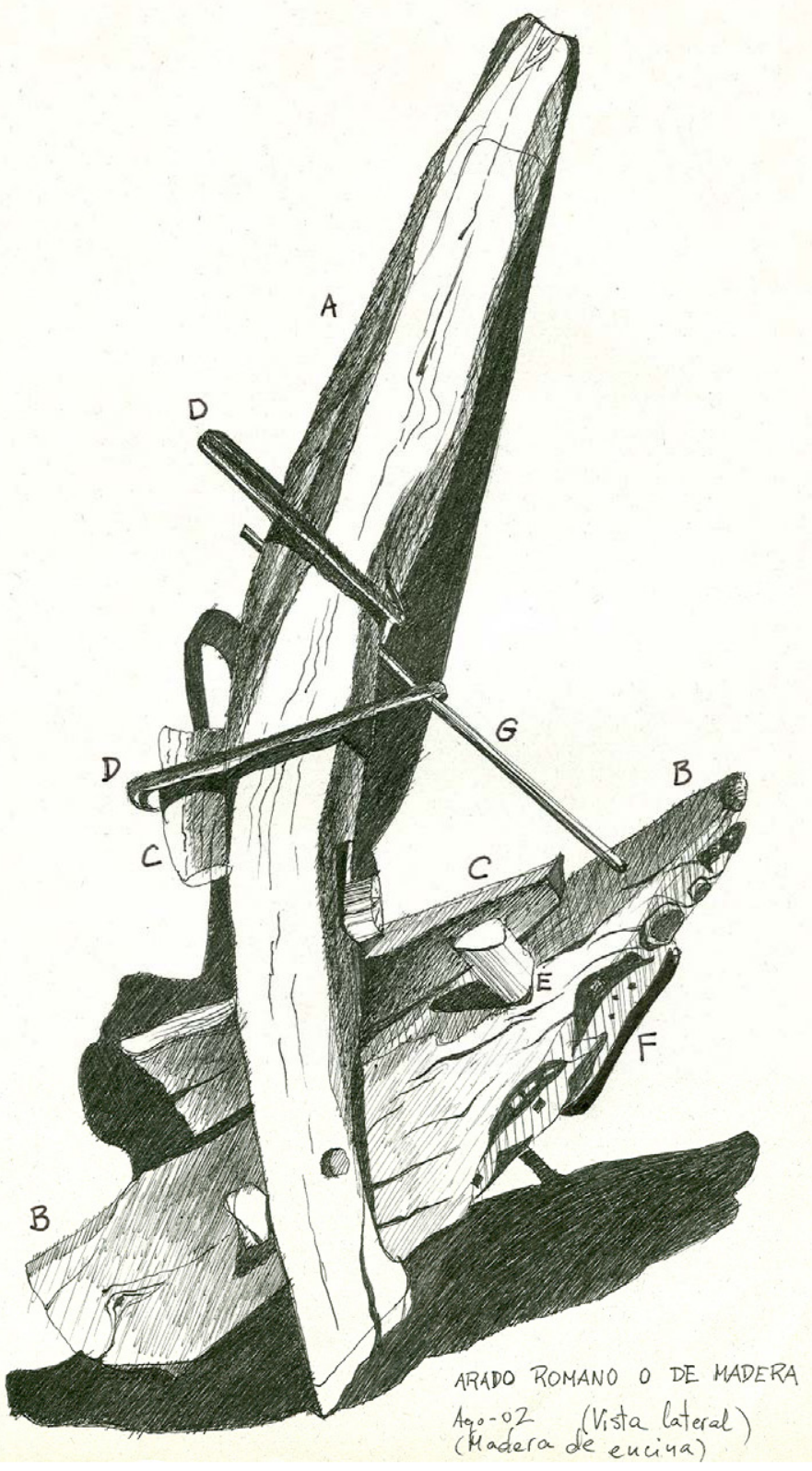

Fig. 9. Arado romano o de madera. E.I. Prada 


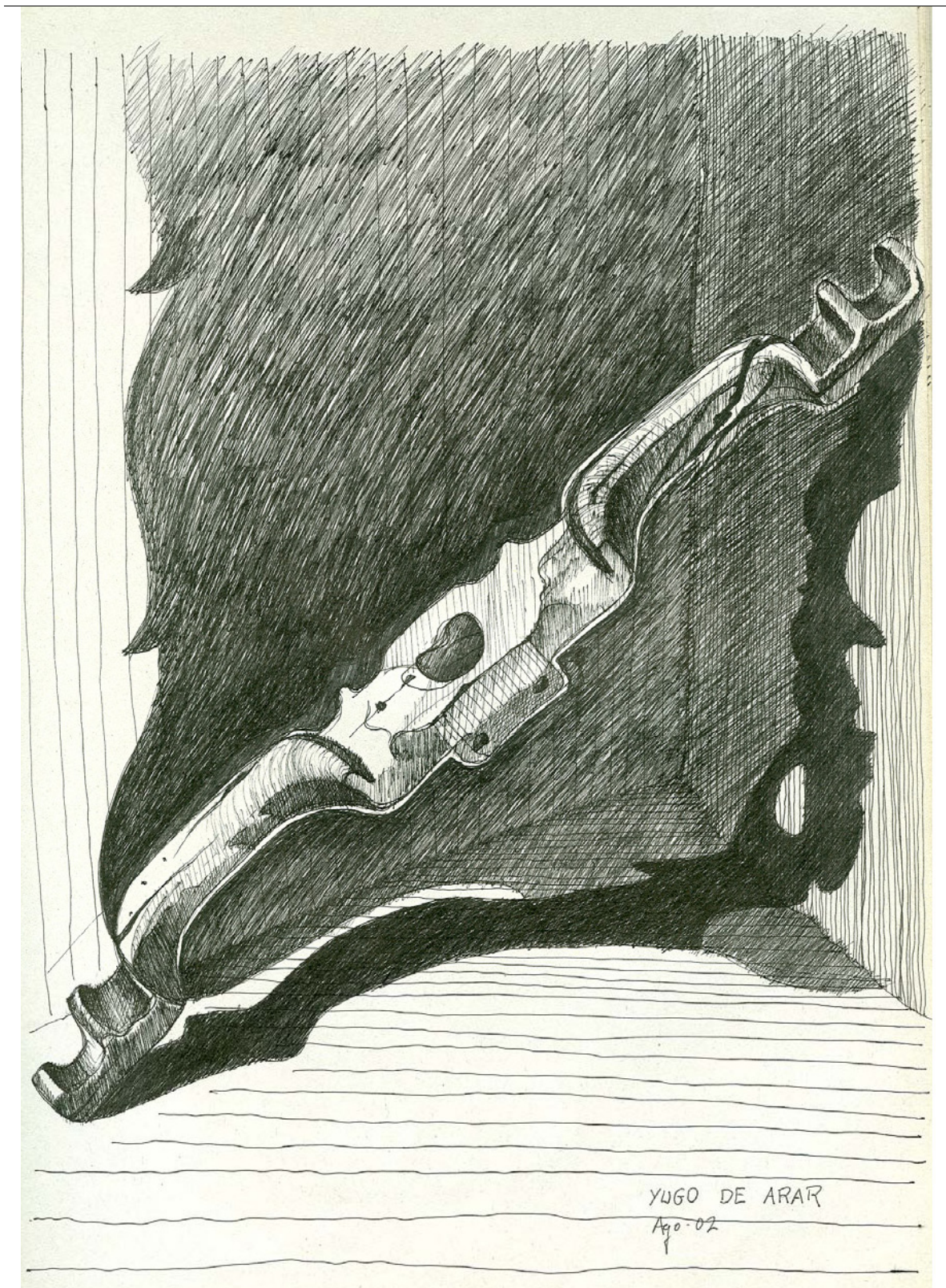

Fig. 10. Yugo de arar. E.I. Prada

Polígonos. Revista de Geografia, 16 (2006); pp. 135-166 


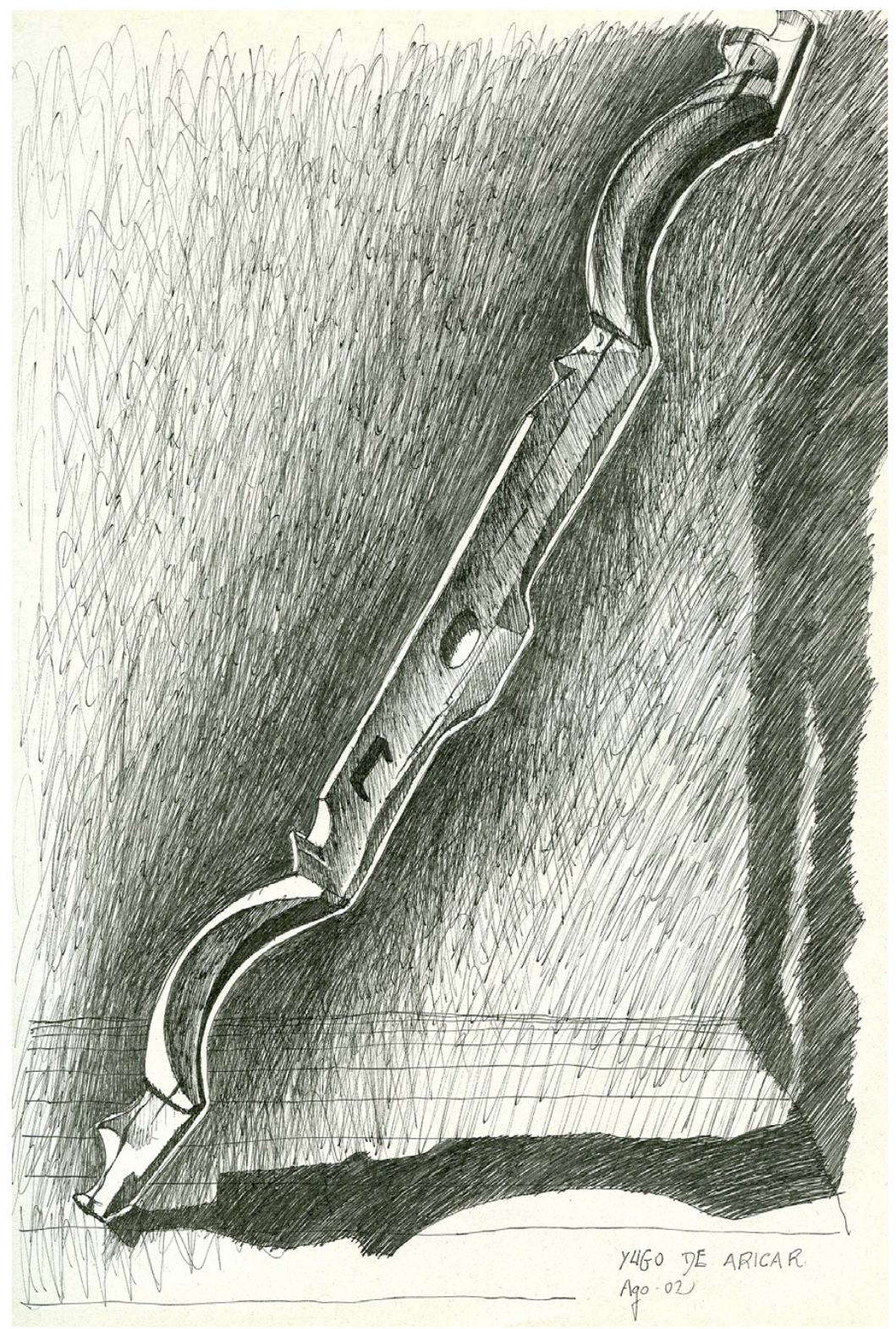

Fig. 11. Yugo de aricar. E.I. Prada 


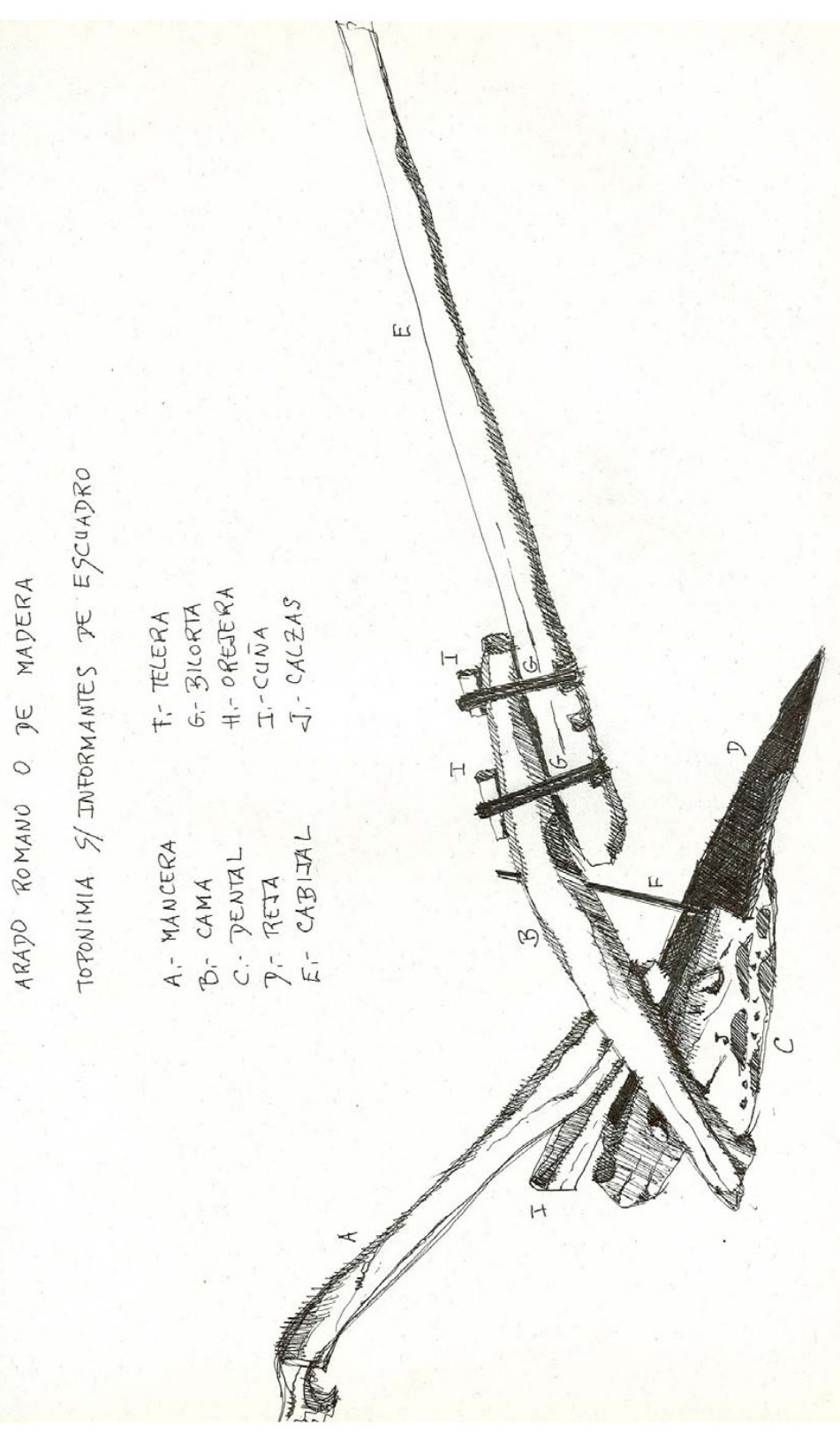

Fig. 12. Arado romano o de madera. E.I. Prada 


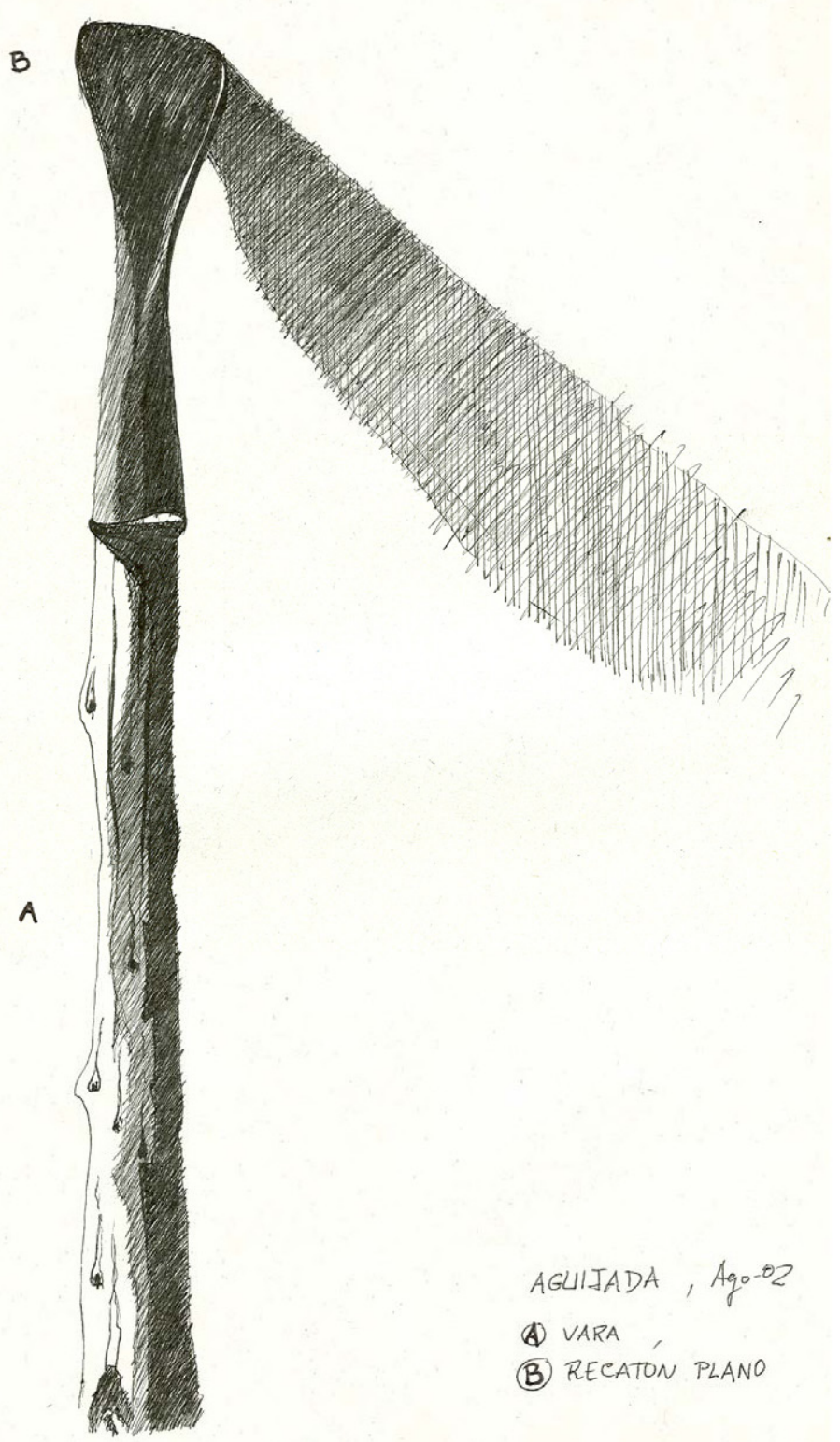

Fig. 13. Aguijada. Vara de madera y recatón de hierro. E.I. Prada 


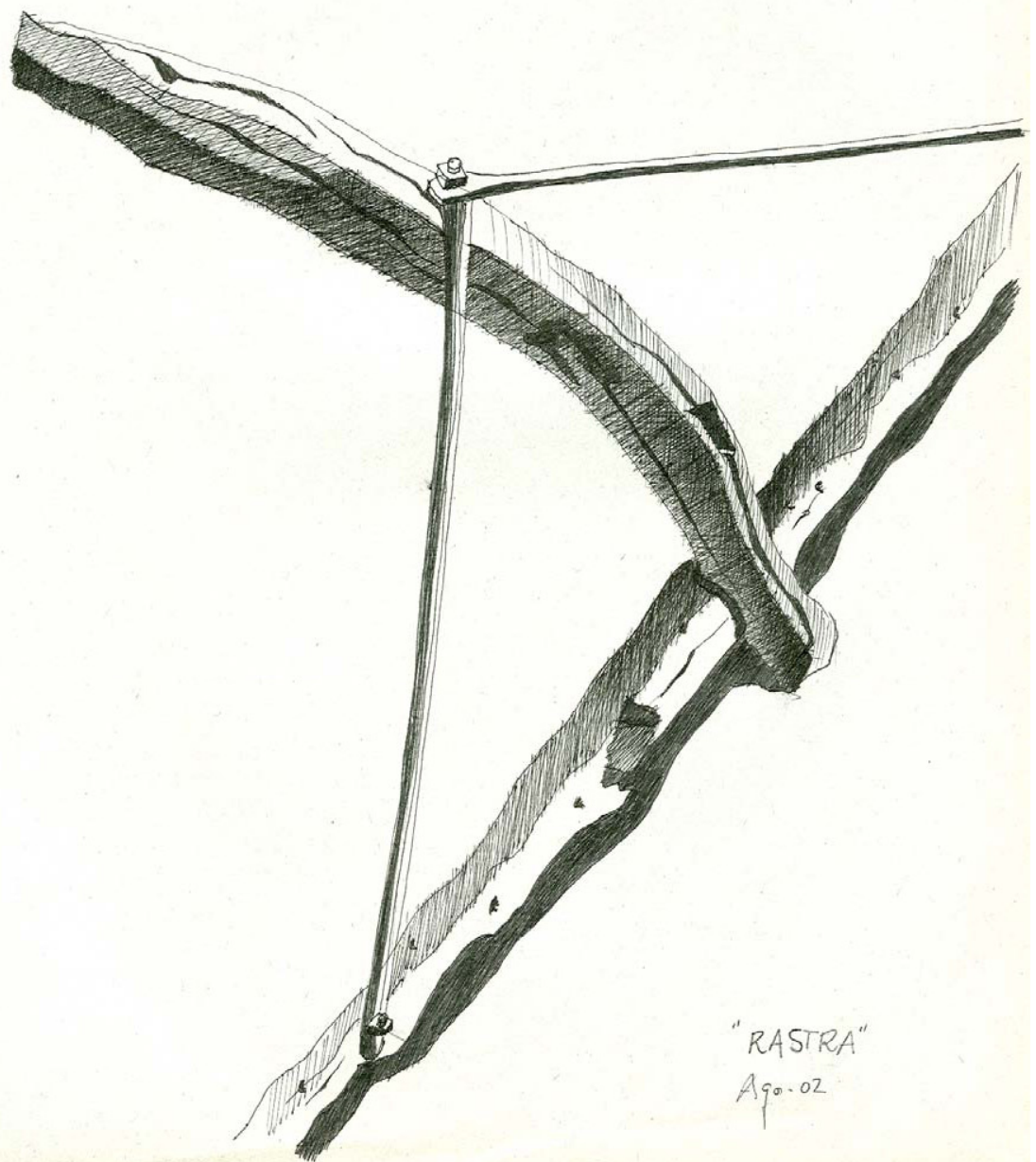

Fig. 14. Rastra de madera. E.I. Prada 


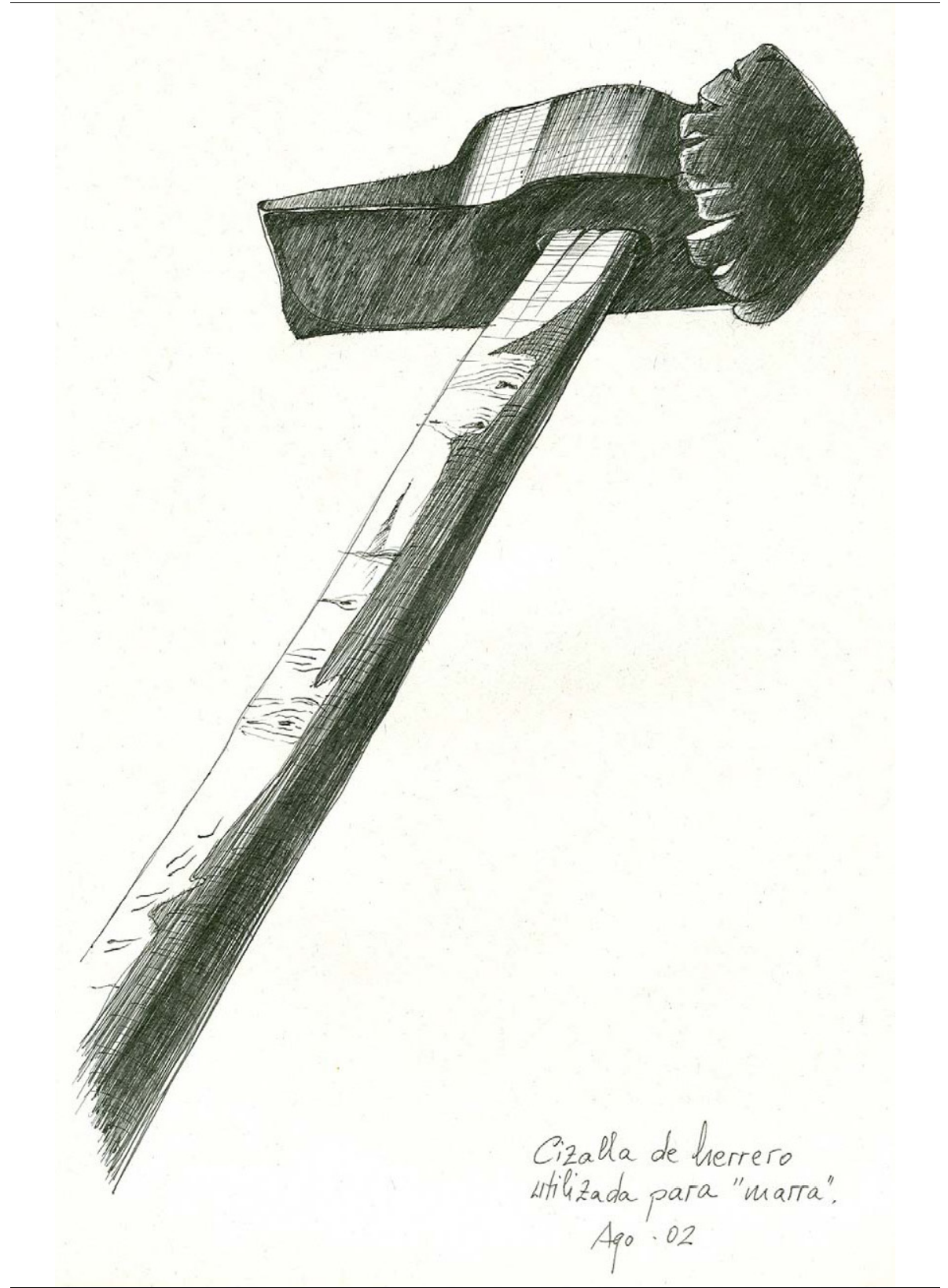

Fig. 15. Cizalla de hierro utilizada como "marra". E.I. Prada 


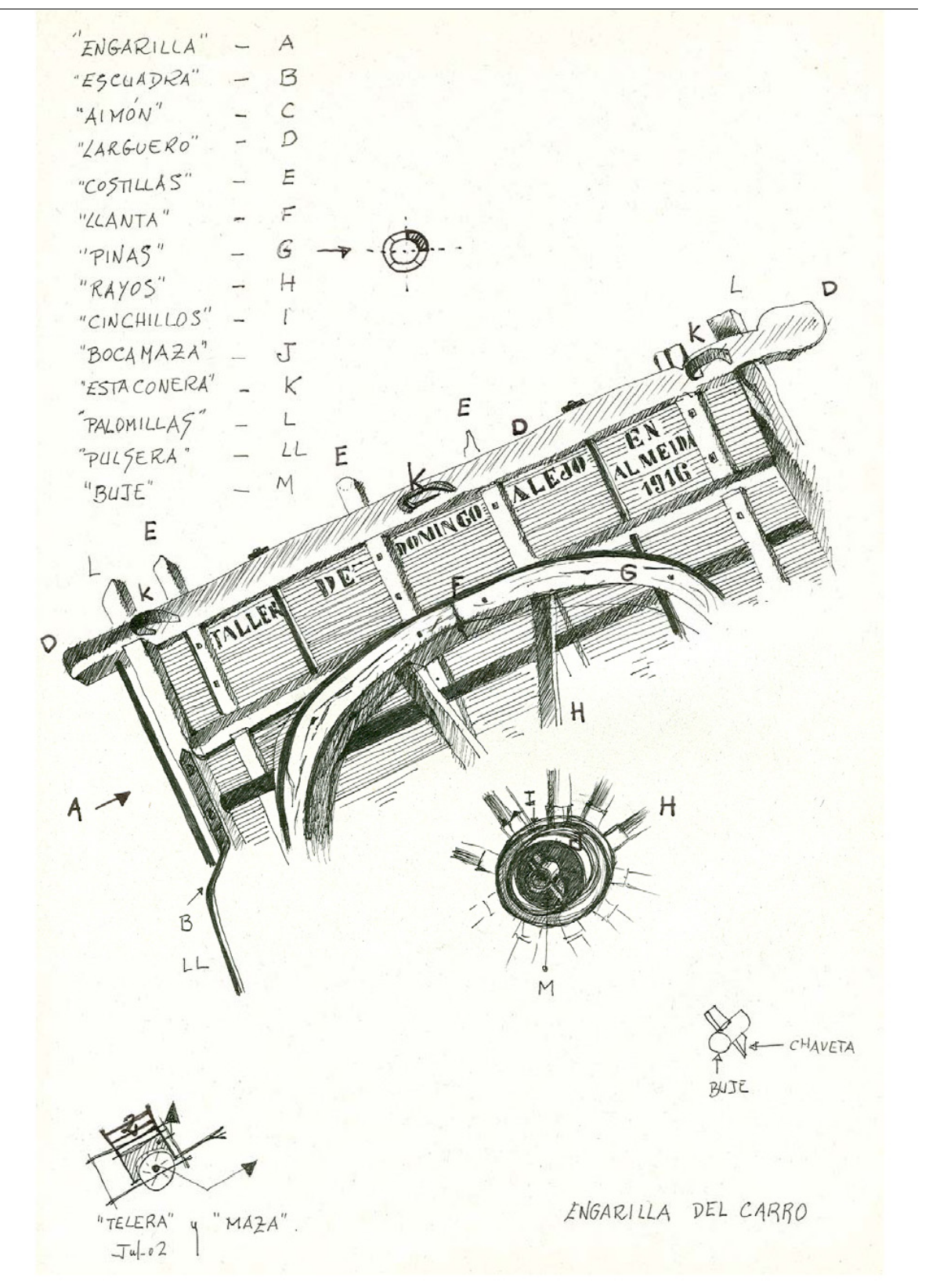

Fig. 16. Carro. E.I. Prada

Polígonos. Revista de Geografía, 16 (2006); pp. 135-166 

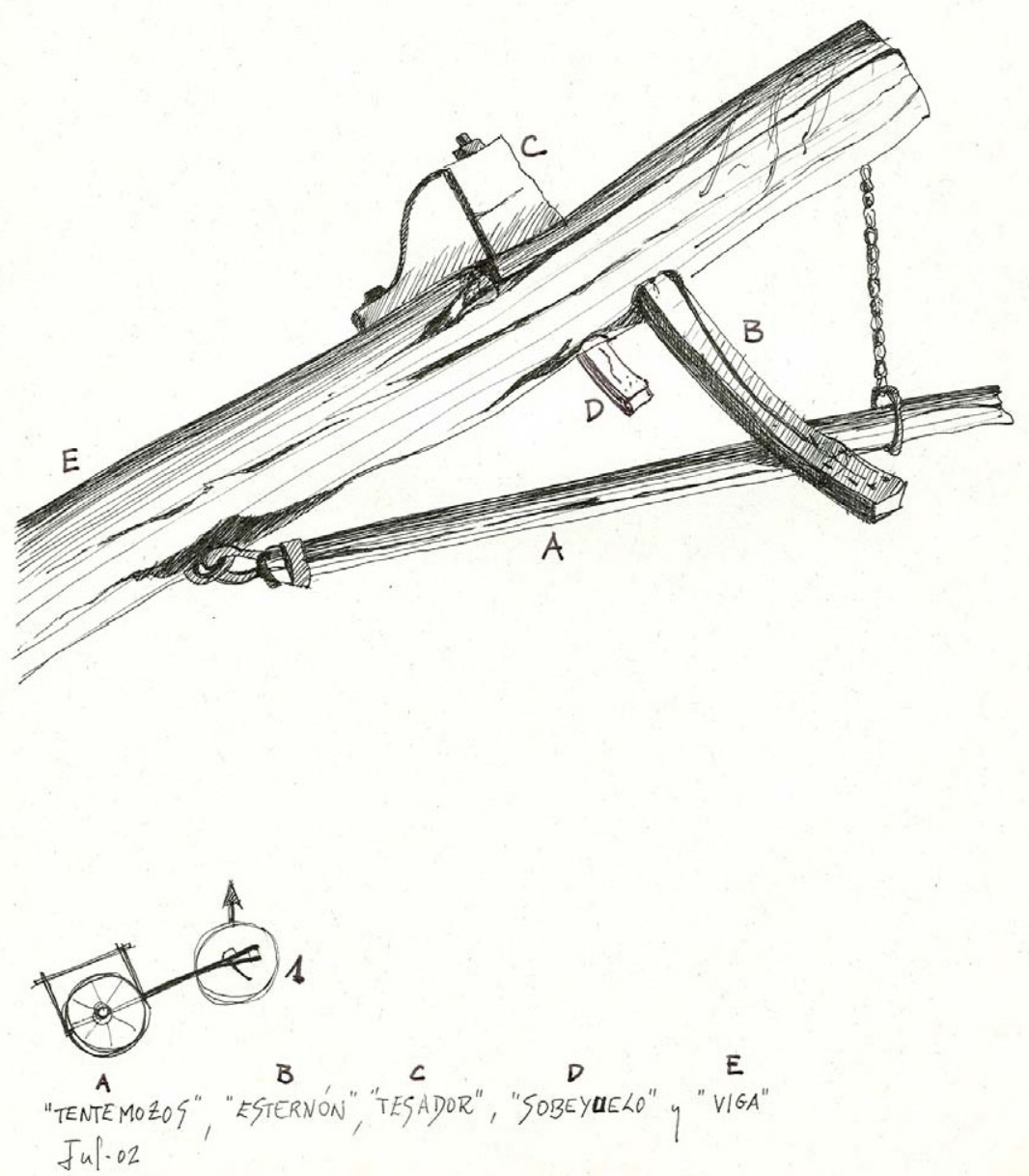

Fig. 17. Viga del carro. E.I. Prada 


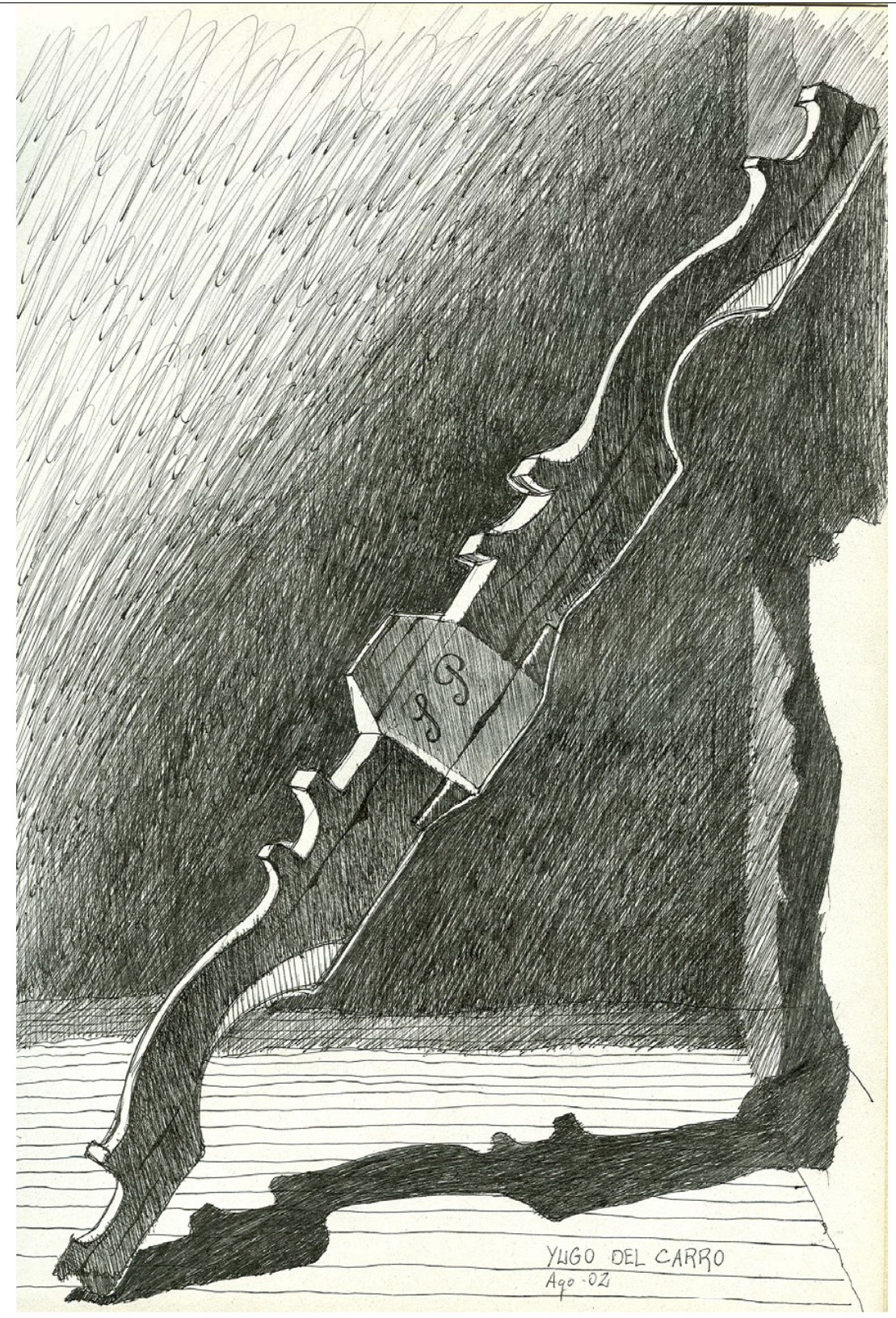

Fig. 18. Yugo del carro. E.I. Prada

Polígonos. Revista de Geografia, 16 (2006); pp. 135-166 


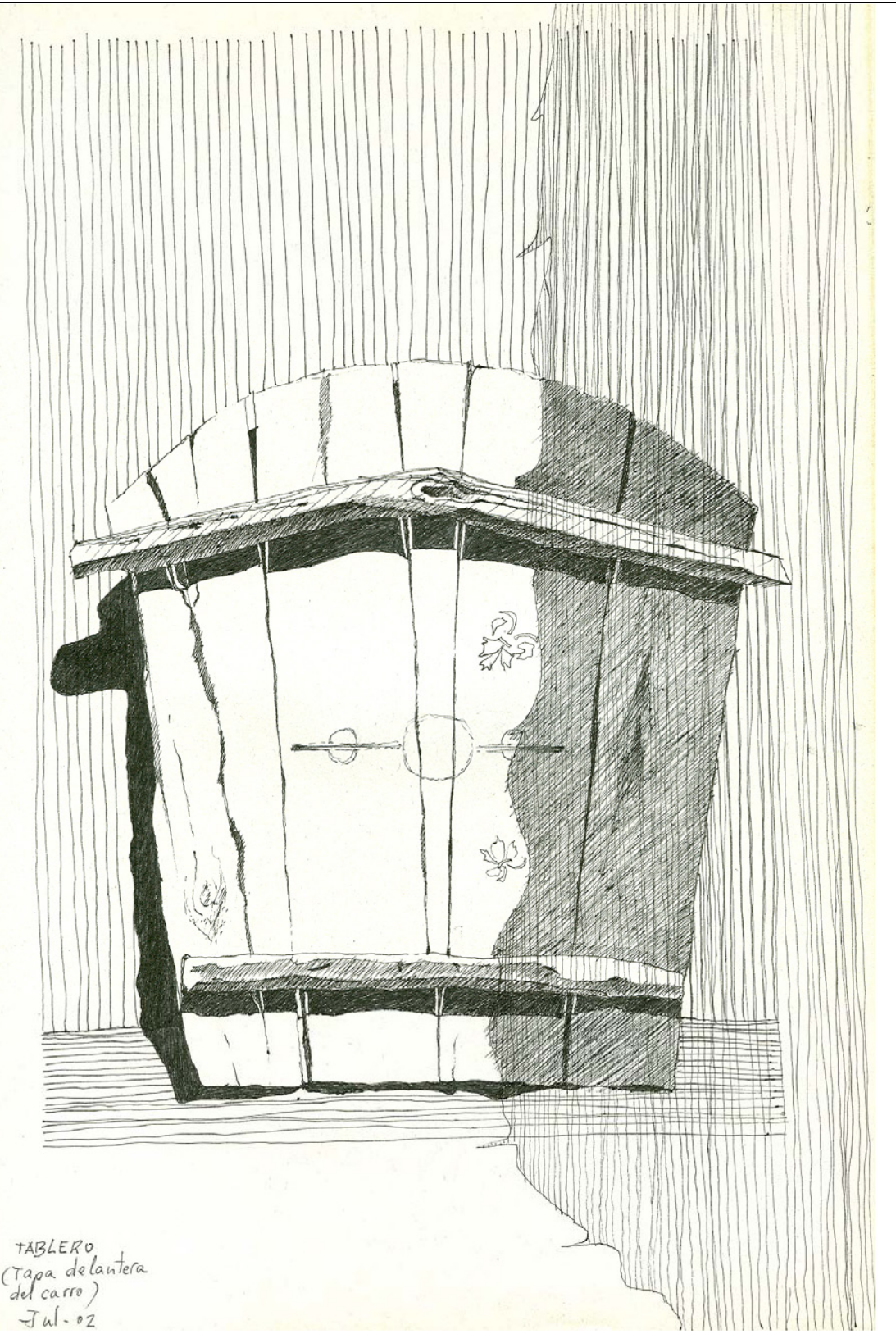

Fig. 19. Tablero. E.I. Prada

Polígonos. Revista de Geografia, 16 (2006); pp. 135-166 


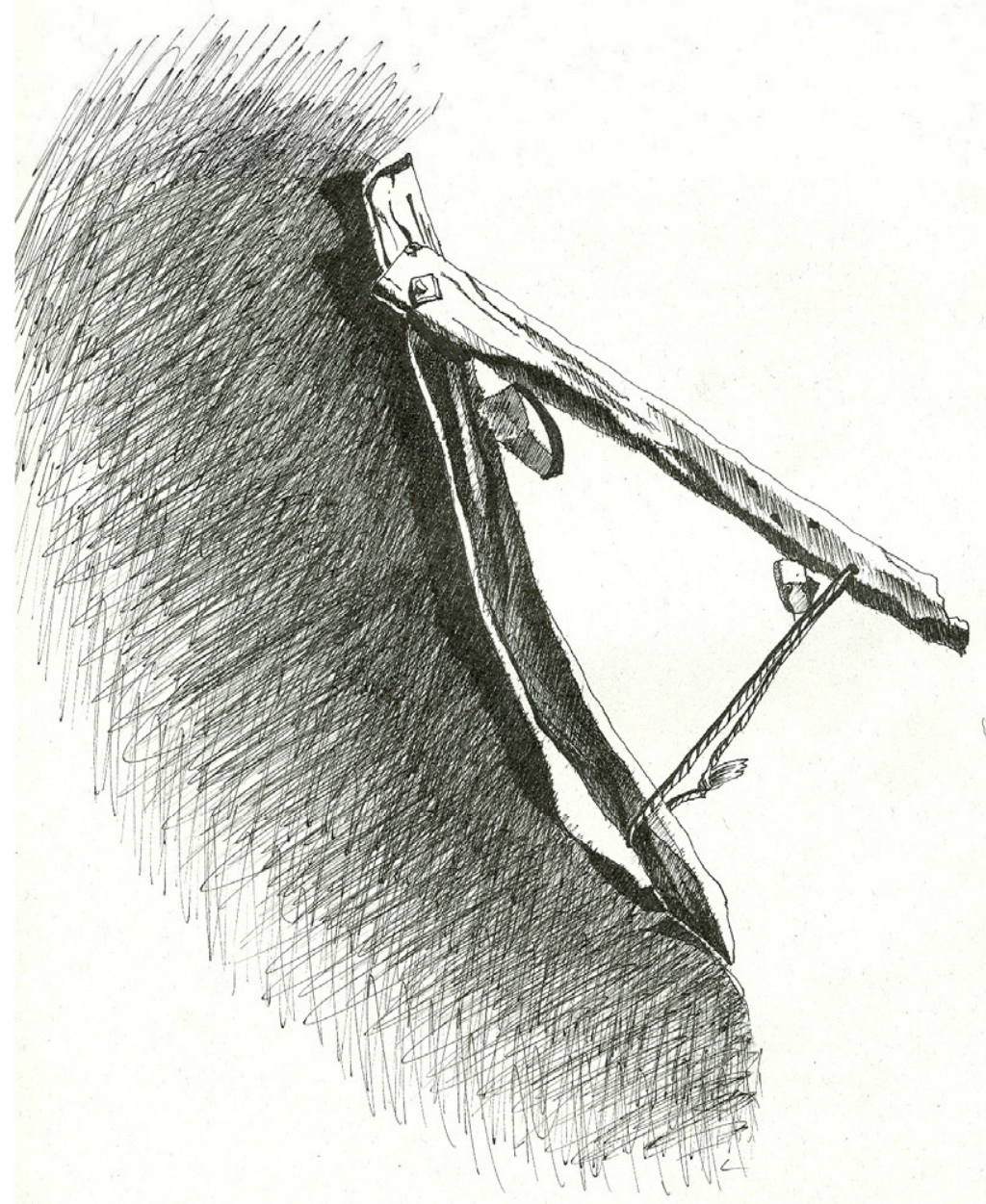

"GATO" de madera

para untar el

carro.

Jul. 02

Fig. 20. Gato del carro. E.I. Prada 